student interest revealed in the 2008 Match until it becomes a flood. Family physicians can help by:

- Serving as preceptors. Contact your local family medicine department, which extends its reach to medical students through volunteer preceptors.

- Getting involved with a nearby family medicine interest group (FMIG). Most medical schools have FMIGs, which are always on the lookout for family physician speakers and supporters.

- Being mentors for bigh-school and college students. Each year, the National Youth Leadership Forum on Medicine seeks out family physicians and family medicine residents to speak at the forum's 23 conferences across the country.

AAFP News Now Staff

From the American

Board of Family Medicine

Ann Fam Med 2008;6:280. DOI: 10.1370/afm.851

\section{MORE FLEXIBILITY FOR MC-FP PARTICIPANTS AND FIRST SLEEP MEDICINE EXAMINATION}

\section{More Flexibility for MC-FP Participants}

The American Board of Family Medicine (ABFM) is continuing its efforts to make the transition to the 'new' Maintenance of Certification for Family Physicians (MC-FP) as straightforward as possible for all Diplomates. The opportunity to gain a 3-year extension to the certificate has been welcomed by the overwhelming majority of MC-FP participants, as well as the continuous upgrades to the software and processes (many of which can be directly traced to Diplomate feedback.)

With the goal of maintaining consistency for all Diplomates, the ABFM announced the following change to the current MC-FP requirements:

- To fulfill Stage One requirements, all participants who begin MC-FP during the period 2004-2010 will have the choice of completing 2 Part II modules and 1 Part IV module OR 3 Part II modules.

This is a change to the original requirement of 2 Part II modules and 1 Part IV module for Stage One. The ABFM Board of Directors decided that all Diplomates should be allowed the opportunity to follow the same rules, and that the options available to the first 2 groups of Diplomates who began MC-FP in 2004 and 2005 should be fairly applied to all Diplomates regardless of year of certification or recertification. This option will allow for more flexibility for participants in Stage One and help ease Diplomates into the MC-FP process during the initial 7-year transition from the traditional recertification process.

\section{First Sleep Medicine Certification Examination Administered}

In November 2007, the American Board of Internal Medicine (ABIM) administered the first Sleep Medicine Certification Examination for 5 cosponsoring boards of the American Board of Medical Specialties (ABMS) to 1,882 of their diplomates. Seventy-three percent of exam takers passed the exam.

The certification exam was developed jointly by the American Board of Family Medicine (ABFM), the ABIM, the American Board of Pediatrics (ABP), the American Board of Psychiatry and Neurology (ABPN), and the American Board of Otolaryngology (ABOto). It replaces the exam given since 1978 by the American Board of Sleep Medicine.

Of the 1,882 diplomates who took the exam, 1,228 were from ABIM, 460 from ABPN, 83 from ABP, 78 from ABOto, and 33 from ABFM. The 33 ABFM candidates seeking certification in Sleep Medicine are currently certified in family medicine, and 18 of these candidates successfully passed the examination.

Certification in Sleep Medicine is designed to recognize excellence among physicians who provide specialized care to patients with sleep problems and specific sleep disorders. Sleep medicine encompasses a multidisciplinary body of knowledge regarding the diagnosis and treatment of sleep problems and disorders and the anatomy, physiology, biochemistry, and pathophysiology of sleep and wakefulness.

The next Sleep Medicine Certification Examination will be offered by the 5 cosponsoring boards in fall 2009. To certify in Sleep Medicine, candidates must fulfill these general requirements:

- Hold a valid certificate in Family Medicine issued by the ABFM;

- Provide satisfactory documentation of the requisite practice experience or completion of formal training requirements through specified practice or training pathways;

- Provide substantiation by local authorities of clinical competence, and moral and ethical behavior in the clinical setting;

- Hold a valid, unrestricted and unchallenged license to practice medicine;

- Pass the Certification Examination in Sleep Medicine.

Note: Diplomates certified by 1 of the cosponsoring boards should contact that board for specific information. Jane Ireland, ABFM 